\title{
Tuning the HOMO and LUMO Energy Levels of Organic Chromophores for Dye Sensitized Solar Cells
}

\author{
Daniel P. Hagberg, ${ }^{\dagger}$ Tannia Marinado, ${ }^{\ddagger}$ Karl Martin Karlsson, ${ }^{\dagger}$ Kazuteru \\ Nonomura, ${ }^{\star}$ Peng Qin, ${ }^{\dagger}$ Gerrit Boschloo, ${ }^{*}$ Anders Hagfeldt, ${ }^{*}$ and Licheng Sun ${ }^{*}, \dagger$ \\ Center of molecular devices \\ Department of Chemistry, KTH Chemical Science and Engineering \\ 10044 Stockholm, Sweden \\ Supporting Information
}

Table of contents

${ }^{1} \mathrm{H}$ NMR and ${ }^{13} \mathrm{C}$ NMR Spectra

${ }^{\dagger}$ Organic Chemistry

* Physical Chemistry 


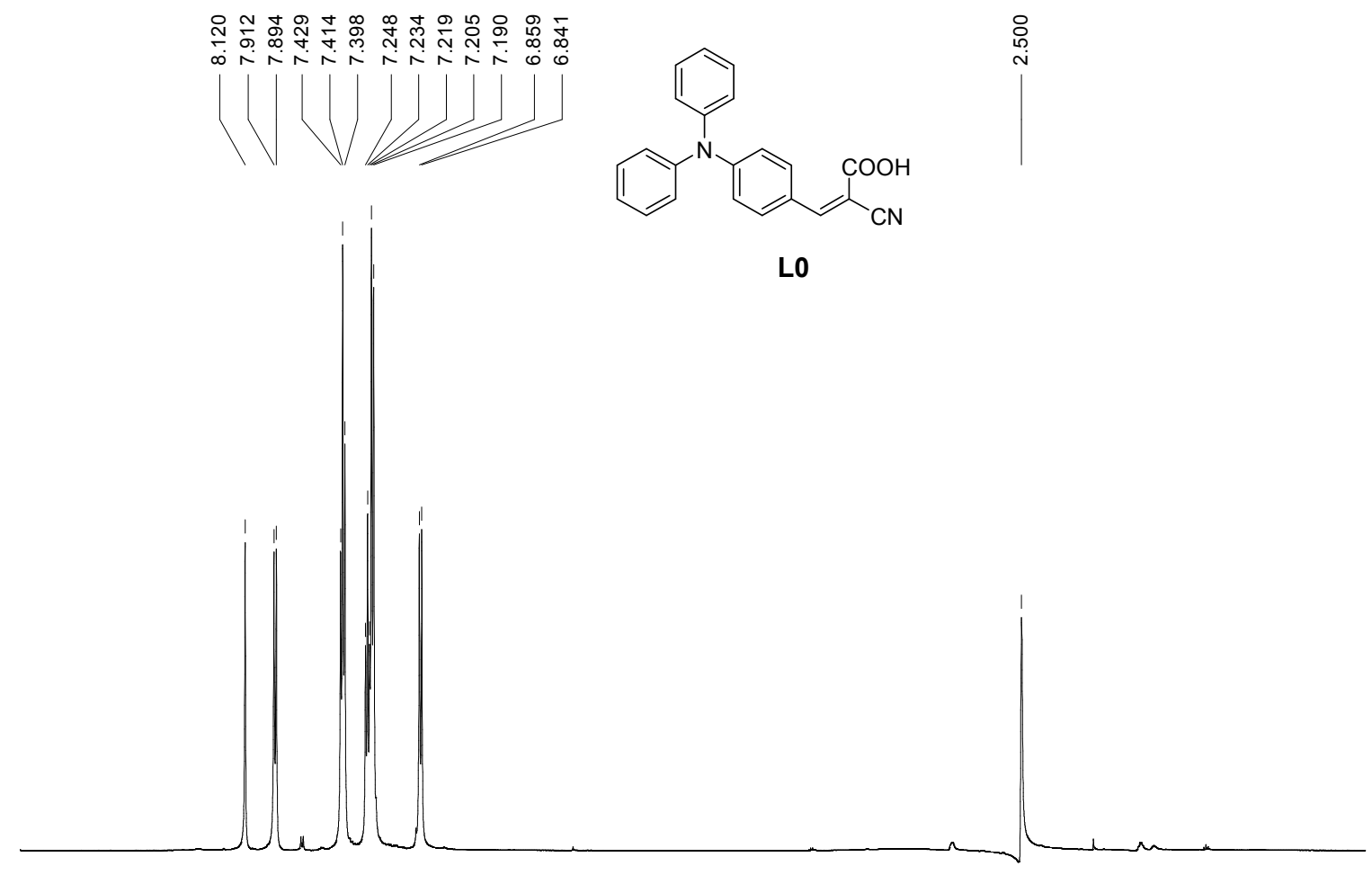

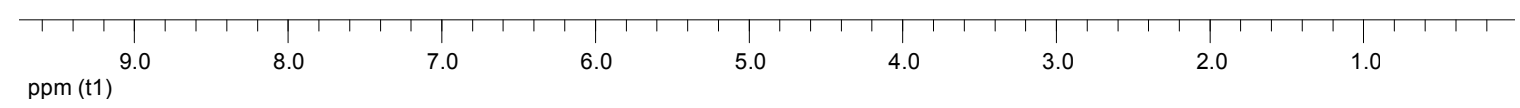

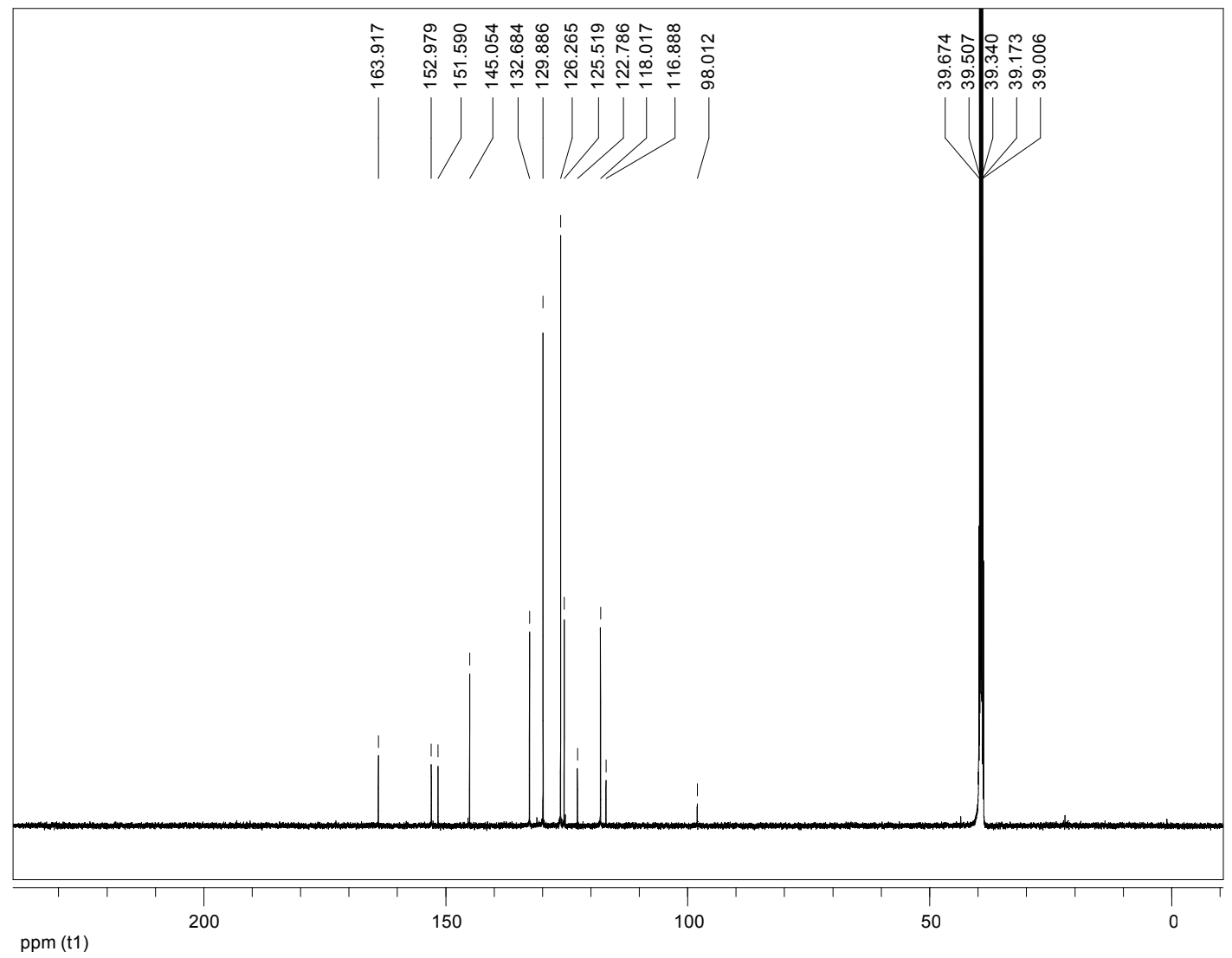




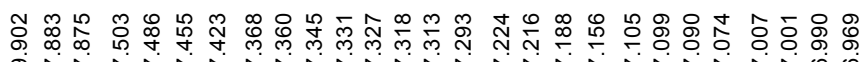

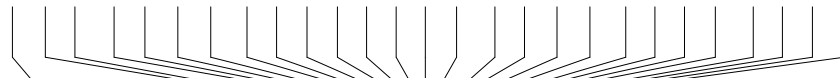

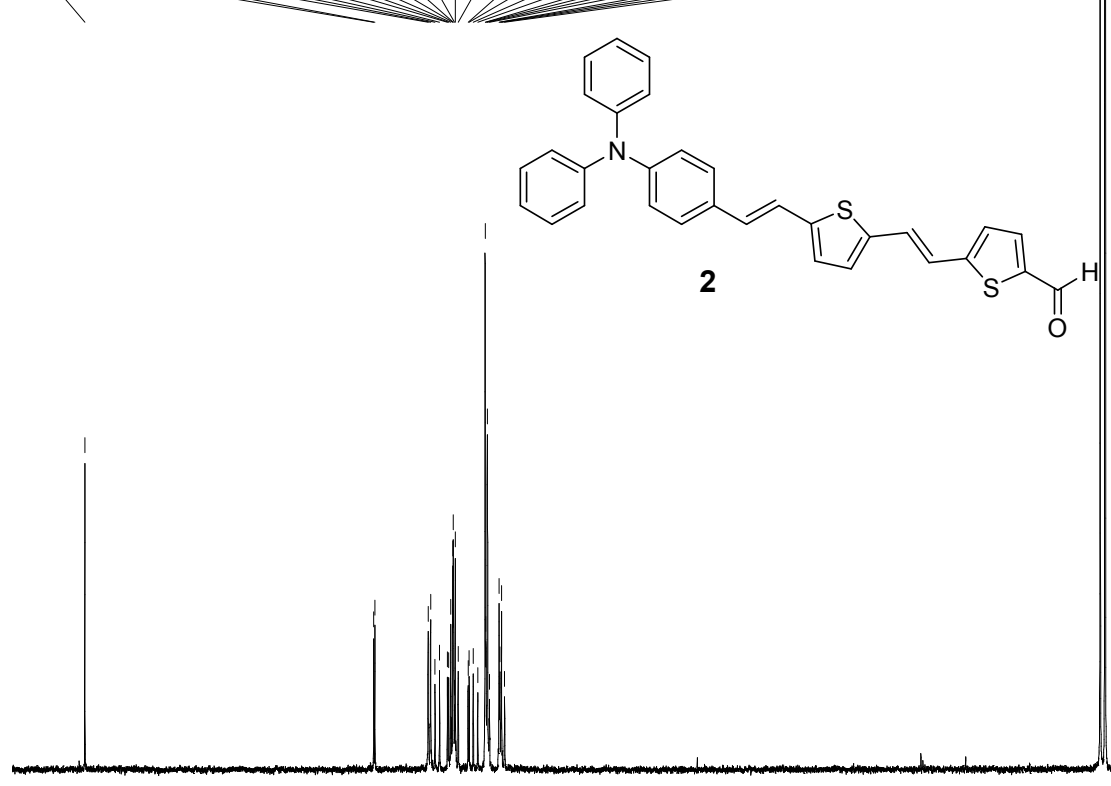

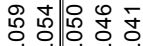

atcos

(1) $\mid 1)$
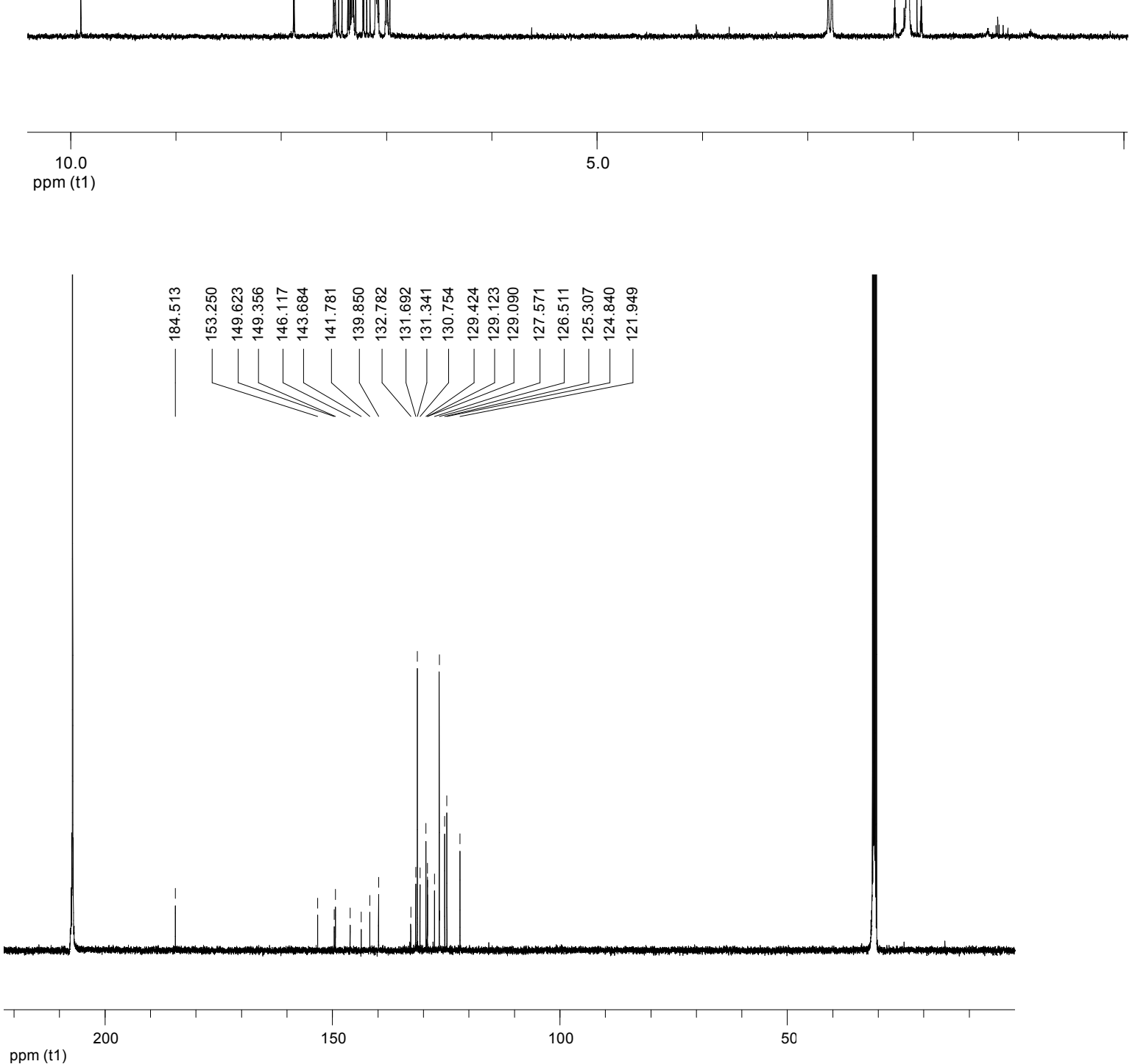


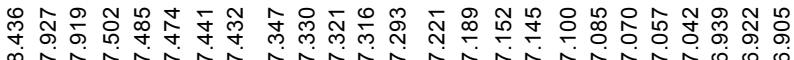
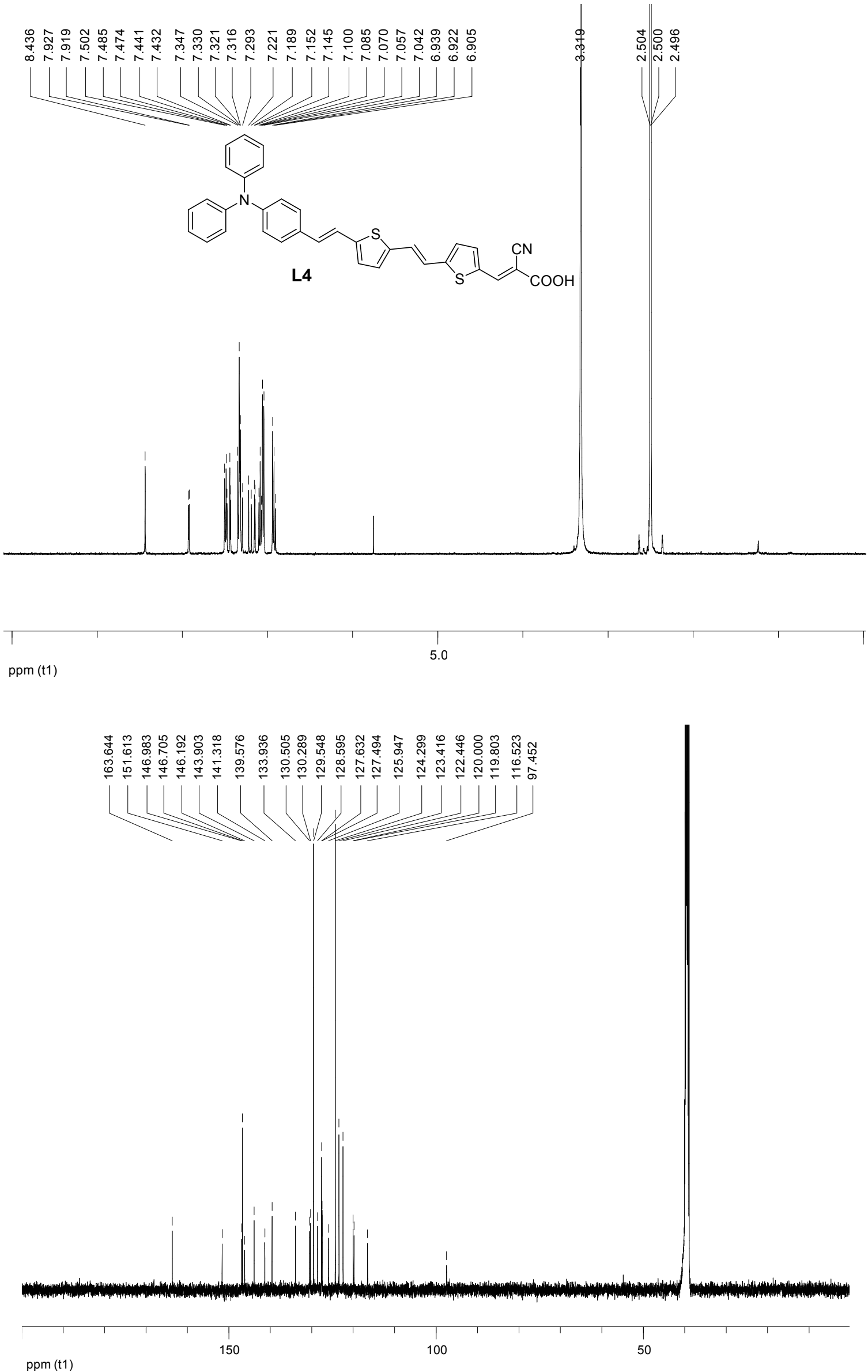

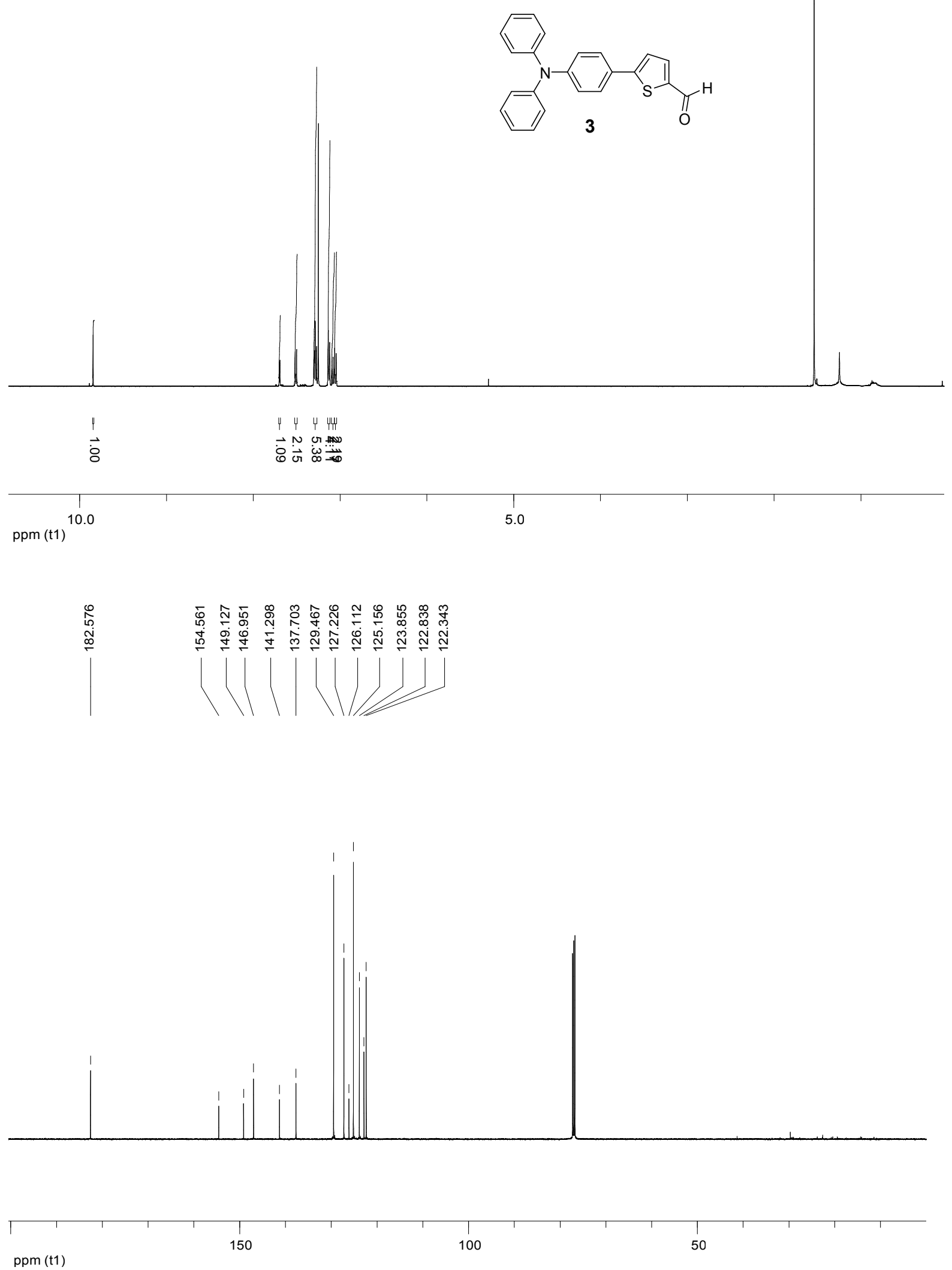

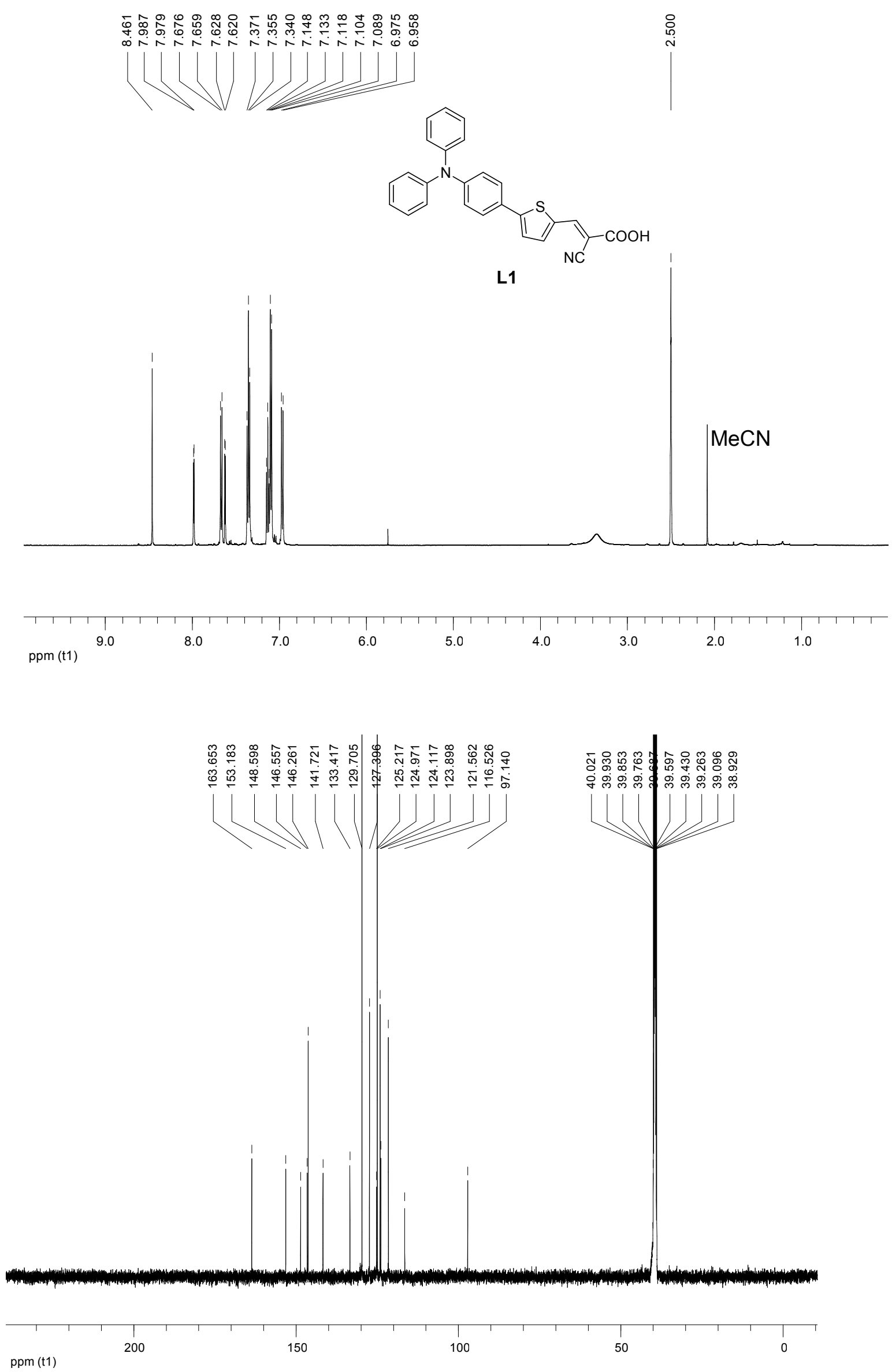

ERROR: invalidrestore

OFFENDING COMMAND: - -restore--

STACK :

- savelevel -

17764

$(\sim d)$

$(\sim d)$

17763

$(\sim \mathrm{C})$

$(\sim \mathrm{C})$

17762

$(\sim \mathrm{b})$

$(\sim \mathrm{b})$

17761

( a)

$(\sim a)$

17760

$(\sim 1)$

$(\sim 1)$

17759

$(\sim)$

$(\sim \overline{)})$

$(\sim \wedge)$

$(\sim \wedge)$

17757

( ])

( ])

17756

$(\sim)$

$(\sim)$

17755

( [)

$(\sim$ )

17754

( Z)

( Z)

17753

( $\sim \mathrm{Y})$

$(\sim \mathrm{Y})$

17752

$(\sim \mathrm{X})$

$(\sim \mathrm{X})$

17751

( W)

$(\sim \mathrm{W})$

17750

$(\sim \mathrm{V})$

$(\sim \mathrm{V})$

17749

( U)

( U)

17748

$(\sim \mathrm{T})$

$(\sim \mathrm{T})$

17747

( S )

( $\mathrm{S})$

17746

$\left({ }^{\sim} \mathrm{R}\right)$

( R)

17745

$(\sim Q)$

( Q)

17744

( P)

( P)

17743

$(\sim 0)$

( O) 